\title{
El programa de ajuste estructural en El Salvador: algunos indicadores de sus resultados económicos*
}

\author{
Ernesto Galdámez
}

\section{A modo de antecedentes}

La cueslión de la pobreza es de vieja data en EI Salvador. No en balde, por antonomasia, ha sido tipificado dentro de la geografia económica mundial como un pais cuyas caracteristicas económicas y sociales lo ubican dentro de la calegoría de pobre, sea que ésta se intitule como subdesarrollo, tercer mundo o hemisferio sur.

Antes, durante y después de la crisis económica, social, política y militar vivida por El Salvador a lo largo de los últimos doce años, el énlasis de la política macroeconómica de los gobiernos en turno, de una manera u olra, se ha concentrado en el logro del crecimiento del producto y de la generación de riqueza. Se ha tendido a asumir axiomáticamente que el cumplimiento de tal objetivo conduciria, de forma aulomática, a elevar el bienestar y la calidad de vida de la población. Mediante la permeabilización de los frutos del progreso hacia los estratos más destavorecidos de la sociedad, en el marco de una concepción de electorebalse, se conseguiria paulatinamente la eliminación de la pobreza. EI hecho irrefutable es que históricamente se han obtenido impresionantes tasas de crecimiento soslenido de la producción nacional de bienes y

- Este ensayo aparece parcialmente reproducido en el documento interno de discusión del Programa de Desarrollo para Desplazados, Relugiados y Repatriados, Subprograma El Salvador, "Propuesta para Operativizar el conceplo de Desarrollo Humano a Nivel Local", Abril/93. 
servicios sin que ello se haya traducido en mejoras generalizadas y sustanciales en el acceso a la salisfacción de las necesidades más elementales de las mayorlas. Por lo tanto, es obvio que el crecimiento es una condición necesaria para el desarrollo, pero en El Salvador no ha sido suliciente para garantizar una vida digna y dignificante a una gran proporción de sus ciudadanos.

Hoy en dia se encuentra bastante aceptada la tesis' de sefhalar a las políticas nacionales implementadas en gran número de paises en desarrollo, principalmente las de carácter económico, como uno de los facfo:res determinanles de la situación de pobreza. Asumiendo como válida tal proposición como enfoque de la realidad, en las siguientes páginas se intentan presentar una aproximación muy preliminar de cuáles han sido los resultados más notorios del programa de ajuste esiructural aplicado en El Salvador por la administración del Presidente Cristiani, a partir de junio de 1989. No se pretende de ningún modo tratar de achacarle a éste la causa última que explica la existencia de la pobreza en el pais. Lo que si se buscará hacer evidente es que los programas de eslabilización y reorientación de la economia por definición, entranan coslos directos para aquellos grupos sociales cuyos recursos son insuficientes para autosostenerse humanamente. Asimismo, se procurará abordar el problema de la eficacia de la aplicación de medios a la consecución de los fines propueslos.

\section{El programa de ajuste estruclural en El Salvador}

\subsection{El plan de desarrollo económlco y soclal 1989-1994.}

Formalmenle el plan² se propone como objetivos globales la creación de las condiciones para alcanzar un crecimiento robusto y soslenido, asi como lambién prelende elevar el bieneslar y calidad de vida de loda la población, especialmenle la que vive en extrema pobreza. En el ámbito económico la estrategia seguida por el Gobierno ha obedecido a dos grandes lineas de acción. En primera inslancia, las acciones se han encaminado a ejecular un programa de estabilización que buscaba reducir - eliminar los principales desequlibrios macroeconómicos y sentar las bases de la recuperación económica Aún y cuando éste se concibió para ser aplicado en forma gradual y no a través de un tratamiento de shock, se sabia de antemano que se estaba imponiendo un allo costo social sobre la población en el corto plazo, particularmente en aquellos sectores de más bajos ingresos. Para remediar parcial e indireclamenle ostos impactos negativos, se establecieron los programas compensatorios de desarrollo de infraeslructura básica, de subsidios directos mediante la repartición de alimentos, de generación de empleos temporales 
obras sociales comunales y de facilitación para mejorar los ingresos con la capacilación de jóvenes. Además con esta misma tinalidad se montó el Fondo de Inversión Social a principios de 1991.

En segunda inslancia, la olra línea de acción de la estrategia se enfocó a la reorienlación lotal del sistema económico hacia la instauración de un modelo de libre mercado donde por medio de la, interacción de oferentes y demandanles, se logrará una eficaz asignación de los recursos de la sociedad. A tal efeclo se planleó que el Estado no intervenga en la economía desempefiando actividades propias a la empresa privada, limitando sus funciones a ser normador de una sana competencia y garantía de un régimen de derecho. Como resullado de esta liberación económica se esperaba incrementar la productividad y la diversificación del aparalo productivo, estimulando el ahorro y la inversión, en el marco de estabilidad con crecimiento.

\subsection{El programa de estabilizaclón}

Inicialmenle este programa eslaba concebido para ser implementado durante los primeros 19 meses de administración del partido ARENA. La eslabilización descansaba en la aplicación de medidas y acciones enmarcadas en cinco grupos de políticas fundamentales: política de precios, política tiscal, política monetaria y crediticia, políticas del sistema financiero y política comercial.

La política de precios se propuso el restablecimiento de los precios relativos de los bienes y servicios, eliminando en consecuencia la mayoria de controles ejercidos por el Gobierno para su fijación. Además, se procedió a revisar y ajustar las larilas de los servicios de agua, alcantarillados y energía eléctrica.

La política fiscal se orientó a reducir el déficit del Gobierno central y a mejorar la siluación linanciera de las empresas públicas no financieras. Por el lado de los ingresos, las medidas tomadas buscaban aumentar la recaudación y fortalecer la administración tributaria. Por el lado de los gastos, las medidas pretendian reducir o limitar el gasto corriente del secior público mediante la imposición de un programa de ausleridad.

La política monelaria y crediticia se orientó a adecuar la liquidez al ritmo de la actividad económica, manteniendo un disciplinado control sobre la expansión de crédito para limitar el exceso de demandas y las presiones resullantes sobre la balanza de pagos o sobre los precios domésticos. Los recursos credilicios se destinarían preferentemente hacia actividades productivas, limitando significalivamente el financiamiento del sector público. Además, otro componente importante de la política fue la liberalización de las tasas activas y pasivas de interés a fin de 
mantenerlas positivas en términos reales.

Las políticas del sistema financjero.fueron disefiadas con el principal propósito de modernizar su función intermediadora, procediendo para ello a su desregulación y privatización.

La polílica comercial y de estabilización del sector externo buscaba disminuir el desequilibrio comercial a través de un fomento decidido de las exportaciones. En tal sentido se eliminarian o reducirian los impueslos a la exportación, se simplificarían los trámites y se eliminarian los controles de divisas. Asimismo, la política comercial se propuso impulsar la eficacia y competilividad del aparato productivo nacional. Para su logro se procedió a la disminución gradual de los aranceles a la importación, se eliminaron los permisos de importación y los depósitos previos obligatorios.

La política cambiaria adoplada por el Gobierno se orientó a la liberalización gradual del tipo de cambio para lograr una tasa única y realista, reflejo de las condiciones prevalecientes en las transacciones exlernas del país.

\subsection{El programa de reorlentación económlca.}

Este se compone de tres grandes grupos de políticas. Por un lado se encuentran aquellas disenadas para reducir la dependencia de la ayuda exlerna, las cuales le dan cubrimiento a tres áreas de acción. En primer lugar se buscó abrir más la economia al comercio exterior. Las herramientas escogidas para tal propósito han sido la adopción de una política cambiaria realista. El eslablecimiento de un marco moderno y transparente para el inversionista extranjero y la puesta en vigencia de un sistema arancelario bajo y uniforme. En segundo lugar, dado que el flujo de divisas provenienles de las remesas de los emigranles se han constituido en la segunda fuenle de ingresos del exterior, se buscó fortalecer los mecanismos inslitucionales para mejorar su captación y poder canalizarlas hacia la inversion. En tercer lugar, se ha procurado obtener un mayor apoyo crediticio internacional de las instituciones multilaterales y un mayor acceso del sector privado al financiamiento externo mediante una liberalización de las operaciones de capilal. El esfuerzo se concentrará en la renegociación de la deuda externa para mejorar la clasilicación del país como sujeto de crédito.

Por otro lado, el segundo grupo de polílicas son las financieras En ellas se reunen un conjunto de medidas de política económica a ser aplicadas en los campos fiscal, credilicio y monelario. En cuanto a las finanzas públicas, se planleó una reforma tributaria encaminada a esta- 
blecer un sistema de base amplia, neutral, basado en pocos impuestos y bajas tasas, fácil y eficiente de controlar. Por la vla del gasto, la política fiscal se orientará principalmente hacia una focalización y más eficiente asignación de recursos presupuestarios en las áreas sociales. La política de endeudamienlo exlerno será orientada a financiar programas de inversión en capital humano, reposición de capital y obras de la infraestnuctura física.

La polílica crediticia se orientará a canalizar los recursos financieros hacia actividades productivas. El déficit liscal ya no podrá ser financiado por el Banco Central de Reserva. La emisión monetaria será compalible con los flujos de recursos externos y con una expansión no inflacionaria del crédito. Las políticas de encaje y redescuento deberán adecuarse a las condiciones de liquidez, previniendo desequilibrios en los macroprecios. La polílica de tasas de interés debe velar para que éslas se manlengan en niveles positivos en términos reales, incentivando el ahorro y evitando la especulación o fugas de capital.

Finalmente, el tercer grupo de políticas lo constiluyen las reformas institucionales y legales para la reorienlación económical Su propósito principal es desregular la economia para mejorar las condiciones de funcionamiento de los mercados. En lal sentido, se planteó la reducción de la intervención del Estado en la economía mediante el impulso a los programas de privalización del sistema bancario y de las empresas eslatales, asi como también a través de la eliminación de los monopolios del comercio exlerior. Del mismo modo, la política gubernamental hacia el seclor agrario reformado se encaminó hacia la distribución masiva de títulos de propiedad, la apertura de nuevas opciones de lenencia y la promoción del empresario agrícola.

\section{Algunos resultados}

Podría ser prematuro avenlurarse a emitir un juicio evalualivo sobre los primeros resullados arrojados por el programa de ajusle estruclural, pues ésle se encuentra todavia en calidad de proceso inacabado debido al relativo corto periodo de tiempo que ha transcurrido desde su puesta en marcha. Hoy se sabe, ${ }^{3}$ en base a la experiencia acumulada en América Latina, que tales procesos de ajuste no son algo instantáneo ni temporal, sino más bien lentos y prolongados. No obstante, hechas estas salvedades, se procederá a revisar los resullados obtenidos por la geslión económica 1989-1992.

Los primeros pronósticos ${ }^{4}$ lanzados sobre los efeclos inmediatos de las medidas đel programa económico de Gobierno, eran bastantes sombrlos. Se anunciaba una contracción severa de la producción, del empleo 
y de los ingresos a raíz del estrujamiento de la demanda agregada interna, producto de una esperada depreciación de la moneda, subida en las lasas de interés, restricción del crédilo y reducción del gasto público. Tal apreciación ${ }^{5}$ se fundamenlaba en la común inclinación de los programas de ajusle estructural, a enfrentar los desequilibrios macroeconómicos a través de la aplicación de políticas cuyos instrumentos son, casi siempre, eslrictamente linancieros.

Echando al traste las predicciones pesimistas sobre la futura evolución de la economía, el producto intemo bruto real ha venido observando un claro comportamiento expansivo. Con la excepción de la tasa experimentada en 1989 el resto del período de ajuste ha significado una franca y sostenida recuperación del crecimiento, después de más de un quinquenio de semiparalización (ver cuadro $N^{2}$. 1). Han concurrido a esta reactivación en la producción de bienes y servicios, dos laclores de primordial importancia. Por un lado, tenemos la creación de un clima más lavorable a la inversión y a los negocios con la llegada al poder del pariido ARENA.. Su politica económica representó un viraje de 180 grados respecto a la administración anterior, brindándole a la empresa privada un panorama de mayor seguridad y certidumbre, sobre lodo porque comparlian básicamente la misma visión del mundo y tenian similar proyeclo de sociedad. Por el otro, el cese del entrentamienlo armado, la firma de la paz y la puesta en marcha del proceso de reconslrucción nacional, han venido a contribuir de forma sustancial al relanzamiento de la actividad económica. Por esla razón, se vuelve basiante dificil distinguir y validar estadísticamente cuál ha sido el verdadero papel del ajuste en el ritmo de crecimiento experimentado.

Según lo revelan los datos ${ }^{6}$ recogidos por las encueslas de hogares y propósitos múltiples, levantadas por el Ministerio de Planificación y Coordinación del Desarrollo Económico y Social, el crecimiento real del PIB trajo consigo una mejoría relativa en la situación del mercado de trabajo. La ocupación a nivel urbano aumentó. La calegoria ocupacional de empleados plenos pasó de 456.996 personas en la encuesta de Octubre/88Febrero/89, a 598,001 personas en la realizada durante el periodo Octubre/91-Febrero/92. En lérminos de lasas medidas en relación al tolal de la población económicamente activa, lal incremento significó ir del $57.8 \%$ al $63.1 \%$ respectivamente. La tasa de desempleo abierto, como era lógico esperar, se contrajo de $8.4 \%$ a $7.9 \%$ para las mismas lechas. Del mismo modo, la tasa de personas en calidad de subocupados, visibles e invisibles, se redujo del $42.2 \%$ al $36.7 \%$, aún y cuando en términos de valores absolutos las cifras se remontaron de 333,125 personas en 1988 / 89 a 349,164 personas en 1991/92, indicando la presencia de un problema de enorme magnitud en la capacidad del aparato produclivo para 
generar sulicientes puestos de trabajo para toda la población.

Al hacer el ejercicio de cruzar los comportamientos de las tasas de crecimiento del PIB, del empleo pleno, de la subocupación y del desempleo abierto, se puede apreciar con baslante facilidad que no existe una correspondencia direcla entre las velocidades de cambio de las dislinlas variables. Mientras la primera de éstas creció en promedio al $3.2 \%$ anual durante los períodos en cuestión, las olras lo hicieron a la zaga con $2.6 \%$ $(-2.7) \%$ y $(-0.25) \%$, respectivamente. El punto de londo al sehalar estas diferenciales consiste en hacer un llamado de atención para no preocuparse exclusivamente por ver cuánto se crece. Es igualmente importante conocer el tipo de crecimiento que se está logrando con la estrategia del ajusle para saber determinar si ésle es genuino o es espurio.

Es conveniente incorporar a esta allura del análisis una acotación de mucha relevancia. La era del ajusle estructural en El Salvador ha estado ligado a un crecimiento real e ininlernumpido de la producción, de acuerdo a las estadísticas oficiales. Lo curioso del caso es que paralelamente a la subida del PIB, los salarios mínimos reales se han mantenido en una especie de caída libre. A nivel urbano, el salario pasó de un promedio de $\$ 170.5$ colones mensuales en el periodo previo al ajusle a $\$ 107.8 \mathrm{men}$ suales ya cuando este último se habia implementado, deteriorándose su poder adquisilivo en más de una tercera parte (ver cuadro N. 1). A nivel rural, la siluación ha sido aún más precaria porque ahi la remuneración al factor trabajo ha sido tradicionalmente por un monto inferior. Este se comprimió de $₫ 78.5 \$ 56.5$ colones mensuales para los mismos períodos analizados (ver cuadro 1 ).

Cabe anadir que en este pais la mano de obra asalariada presenta únicamente una fracción de la oferta laboral tolal, pues, por ejemplo, en el sector informal ${ }^{7}$ del área urbana Irabaja, como mínimo, el 50\% de la población económicamente activa. Por esta razón, cuando se hace referencia a la evolución de los salarios reales, únicamente se esla planteando la situación de los empleados en el secior formal de la economia.

Merece la pena apuntar, enlonces, que el programa de ajuste ha conllevado la aplicación de una política implicita de contención salarial," caracterizada por ir elevando los salarios mínimos con rezago y en una proporción menor a la experimentada por el nivel general de precios inlernos. Es razonable suponer, por lo tanto, que dicha política haya provocado un efecto redistributivo del ingreso nacional, no precisamente en la dirección de favorecer a los sectores de más bajos recursos. Vale aclarar, por cierto, que el programa de ajusle estructural ${ }^{9}$ no postula ni pretende buscar como su objetivo la distribución equilaliva de los beneficios provenientes del crecimienlo. Por el contrario, éste ha tendido a reforzar la 
exislente desequilibrada distribución de la riqueza a través de una desigual distribución social de su cargo y de sus costos. Esta realidad es muy bien descrila por Ibisate cuando atirma al respecto que "La población sólo comprende que cada día su salario no le alcanza para sobrevivir y que debe buscar cualquier forma de ingresos para cubrir sus necesidades básicas. ${ }^{10}$

Otra cuenta nacional donde se puede ver reflejado el impacto negalivo de las medidas de estabilización, es el consumo privado real per cápita. Efectivamente, el esfuerzo del gobierno por reducir los gasios en la economia ha sido exitoso, al menos en cuanto se refiere a comprimir esla variable. El consumo privado real per cápita cayó de un promedio de $\$ 465$ colones mensuales durante el periodo de preajusle, a $₫ 458.8$ colones posteriormente (ver cuadro $\mathrm{N}^{\mathrm{2}}$. 1). Teóricamente, tal resultado podria leerse como el indicio de un polencial incremento en la lormación de ahorro privado, sobre todo cuando el PIB real per cápila se ha mantenido creciendo durante el período (ver cuadro №. 1) y la tasa de interés ha tendido a mantenerse positiva en términos reales. Sin embargo, tal compontamiento del consumo parecería eslar, a todas luces, mucho más relacionado al achatamiento del poder adquisitivo de la masa de salarios que a una decisión racional de los ciudadanos por máximizar el plazo en el sistema bancario.

Los logros del programa económico de gobierno en el ordenamiento interno de aspectos macroeconómicos han sido bastante limitados. A pesar de convertir el combate a la inflación en una de sus máximas prioridades, el índice general de precios al consumidor ha continuado variando, en promedio, a una tasa muy similar a la observada en el periodo de preajuste. Porque la inflación se haya reducido en $4 . \%$, pasando del $22.1 \%$ al $18.1 \%$ (ver cuadro $N^{2} .1$ ), no autoriza a pregonar que ésta ha sido controlada. No obstante, seria indebido no mencionar aquí que las medidas deflacionarias orientadas a mantener la disciplina monelario-financiera, restringiendo el acceso al crédito al sector público y regulando la liquidez en la economía, han posibililado que el repunte de la producción nacional no vaya acompanado de un proceso hiperinflacionario. Es decir, pese a haberse desatado enormes presiones inflacionarias por el lado de la oferta con la liberización de los controles de precios, con la elevación de las tarifas de energía eléctrica, agua y transporte, con la eliminación de la mayoría de subsidios, con la subida de la tasa de interés, con la devaluación cambiaria, etc. a la economia no le ha locado atravesar por un período mucho más traumático en lérminos de una recesión generalizada y de una pérdida mayor del poder adquisitivo de la población.

Tampoco en el tratamiento del olro componente del desequilibrio in- 
terno se ha corrido una mejor suerte con el ajuste. La política fiscal se ha concentrado infructuosamente en reducir el délicit en el flujo de caja del Estado. En valores corrientes el saldo en rojo se disparó de un promedio anual de $\$ 708.6$ millones durante los antos de preajuste, con una marcada propensión a la baja, a $₫ 1,812.5$ millones (ver cuadro № 1 ) cuando el gobierno emprendió un tipo de cruzada para su eliminación. En olras palabras, las cifras anteriores significan que el exceso de gaslos sobre los ingresos duranle este período reportan un total acumulado de $₫ 7,250.2$ millones, equivalentes a más del doble del monto acumulado a lo largo de un quinquenio completo. Lo más preocupante de tal eslado de cosas es que el déficit se ha deslinado, en su mayorla, a financiar gasto corriente y no la formación de capital. Sin embargo, al relativizar el déficit se nos esboza un panorama un tanlo ambiguo. Al medirlo en comparación al PIB las proporciones bajan de un promedio anual del 4.0 al $2.8 \%$ (ver cuadro $\mathrm{N}^{2} 1$ ). Desde luego que en términos de exportaciones totales," el déficit subió del $21.0 \%$ al $37.9 \%$, respectivamente, para los periodos en cueslión. Este úllimo indicador pudiera estar sugiriendo un mayor grado de aproximación a la realidad fiscal en tanto la pauta seguida durante el periodo de ajuste ha sido la contratación de préstamos con la banca internacional para linanciar la mayor parte del déficit.

El problema de la política fiscal adoptada por el lado de los ingresos, ${ }^{12}$ ha sido la prolundización de una esiructura tributaria regresiva que privilegia el aumento de la recaudación por la vía de los impuestos indireclos y no de los direcios. No sólo se retormó la ley de papel sellado y limbres para eliminar exenciones, sino que posleriormente se sustituyó a ésta por la entrada en vigencia del impueslo al valor agregado (IVA). Además, se redujeron las tasas impositivas a la renta, al patrimonio y a las exportaciones de calé. También se eliminaron los gravámenes a las herencias y sucesiones. El sesgo de este conjunto de medidas ha descargado, ciertamente, el peso del ajuste sobre los hombros de quienes no cuentan con los mecanismos para Irasladar a otros el pago efectivo de los nuevos impuestos.

Ojalá el déficit fiscal experimentado a lo largo de los ochenta y en los primeros anos de los noventa, después de todo, hubiera servido como una transferencia direcla de recursos para el desarrollo socioeconómico de las poblaciones donde hay más carencias de bienestar malerial. Asi se lendrán, al fin y al cabo, una justificación élica y humanislica de suficiente peso. Pero, desgraciadamente, el gasto público se dedicó principalmenle a cubrir los rubros de detensa y seguridad, asi como lambién a pagar el servicio de la deuda interna y exlerna contraída por el Estado. Por el contrario, las partidas destinadas a educación, salud, asistencia social, vivienda, trabajo y previsión social han venido reduciéndose secu- 
larmente. Asi vemos que, durante el perlodo de ajuste, el gasto social como porcentaje del PIB ha venido ocupando una menor proporción de éste, pasando del 4.0 al 3.1.\% (ver cuadro №. 1).

Quizás la Irustración más grande del programa de estabilización y reorientación económica se halle en su incapacidad manifiesta para resolver el creciente desequilibrio externo. Por lo visto, la reducción arancelaria y la devaluación de la moneda no han sido suficientes ${ }^{13}$ como para generar, automática y autonómamenle, una mayor eticiencia y produclividad de la producción nacional, condición, que supuestamente, posibilitaría una penetración agresiva de nuevos mercados intemacionales por parte de las exportaciones, principalmente de las no tradicionales. Lo cierto es que la brecha comercial, lejos de acortarse, tendió en forma sostenida a hacerse mucho más profunda, alcanzando niveles nunca antes registrados. Esle déficit se remontó con el ajuste de una cifra anual promedio de US $\$ 301.4$ a US $\$ 798.1$ millones de dólares (ver cuadro $\mathrm{N}^{2}$ 1). Para 1992 dicho monlo ascendió a US $\$ 1,028.4$ millones de dólares (ver cuadro $\mathrm{N}^{2}$ 1).

Ahora bien, en la explicación de lal fenómeno intervienen varios factores. En primer lugar, pese al hecho de haberse dejado el tipo de cambio al libre juego de oferla y demanda, el Banco Cenlral de Reserva ha "supervisado" su flucluación, regulando via encaje legal u operaciones de mercado abierlo la paridad de la moneda trente al dólar. Reforzando estas acciones, ha concurrido al pais un llujo masivo de remesas lamiliares $^{14}$ procedente de los Estados Unidos de América, las cuales durante el último año ascendieron a la no despreciable suma de US $\$ 708.6$ millones de dólares. Ambos factores contribuyeron a hacer prevalecer la sobrevaloración cambiaria como constante histórica's en el país, estimulando un incremento acelerado de las importaciones. En segundo lugar, dado el alto componente importado del consumo en los altos niveles de ingreso y dada la necesidad inherente del aparato productivo de traer del exterior los bienes intermedios o de capilal, se configuro, en conjunlo, un escenario ${ }^{16}$ caracterizado por una demanda de importaciones cuya elasticidad precio es bastante baja o inflexible: En tercer lugar, habria que comprobar empirica y rigurosamenle si nuesiras exportaciones ${ }^{17}$ son también relativamente ineláslicas al precio, lo cual supondría que no aumenlarian mucho ante los estímulos provenientes de una devaluación, ni lampoco disminuirian mucho a consecuencias de una sobrevaloración. Finalmente, no se puede olvidar que los precios internacionales del café se derrumbaron a partir de la ruplura del pacio cafetero a nivel mundial, ocasionando una enorme pérdida al país en el valor de las exportaciones de dicho producto. 
Cuadro No. 1: Algunos Indicadores de la evolución económica

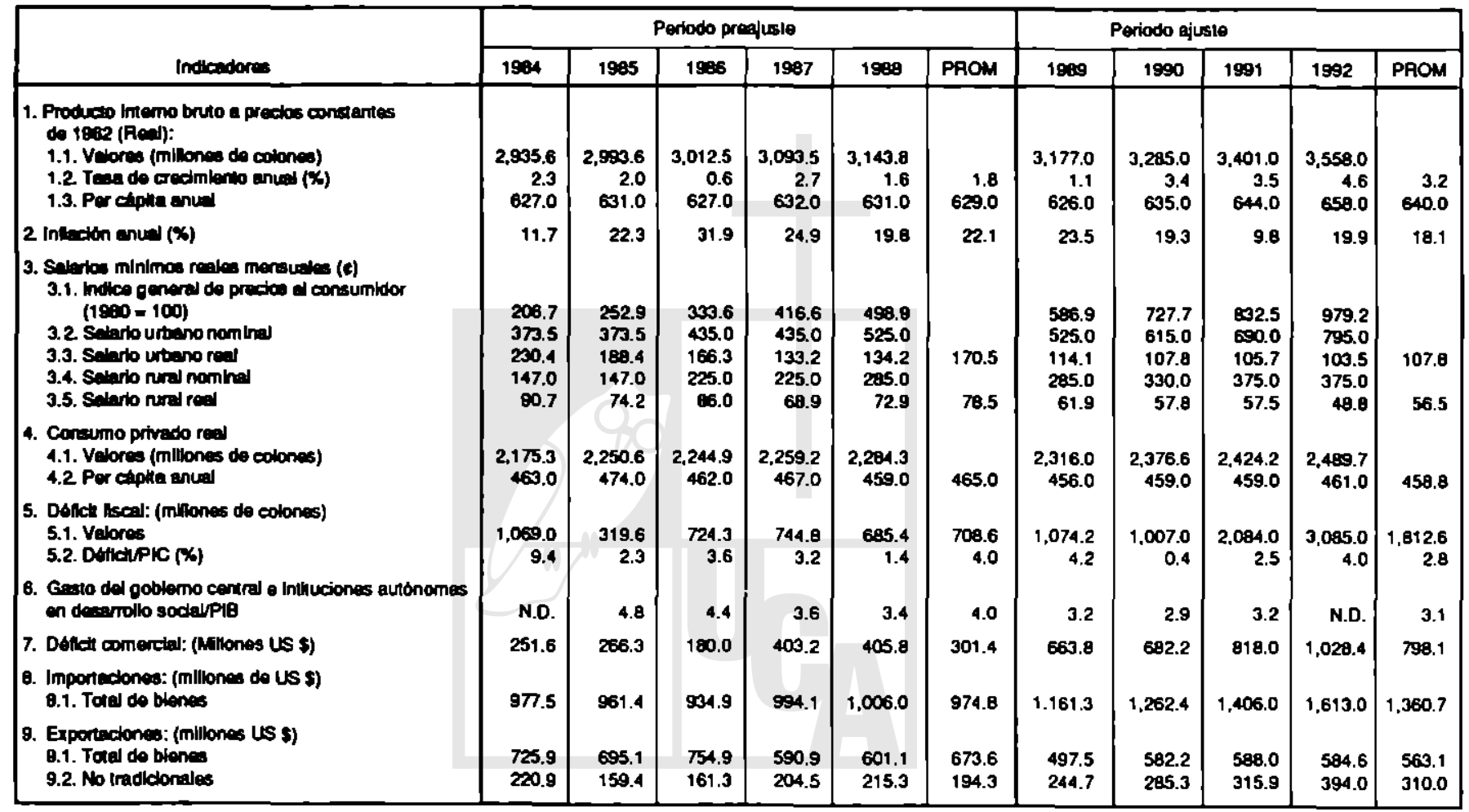

FUEMTE: Rovista trimestral del Banco Central de Resorva.

Dirección de Estadisticzs y Censo, Ministerio de Economla, "Indice de predas al Consumidor" Ministerlo de Ptanilicación y Coordinadón del Desartollo Econónico y Sacial. 
En conclusión podriamos alirmar que, simultáneamente a la puesta en práctica del programa de ajuste estructural en El Salvador, se ha logrado reactivar la economia, mejorar en forma relativa la situación del empleo y disminuir la tasa anual de inflación. No obstante, parece lambién haber jugado un rol determinante en los crecientes déficils de la balanza comercial y de las finanzas públicas. Por otra parte, han sido los trabajadores asalariados a quienes les ha tocado asumir la carga de los coslos sociales de este conjunto de medidas via la reducción del valor de sus remuneraciones, el pago de impuestos mayores y la contracción de su consumo. Ahora bien, en el largo plazo, el mayor costo del ajuste es el costo de no hacerlo.

\section{Notas}

1. Ver "Desarrollo Humano: Informe 1992", publicado para el PNUD por Tercer Mundo Editores, Santa te de Bogolá - Colombia, 1a. Edición en Español, Abril de 1992.

2. El resumen que a continuación se presenta del Plan de Desarrollo Económico y Social 1989 - 1994, está basado en el documento original publicado por el Ministerio de Planificación y Coordinación del Desarrollo Económico y Social, San Salvador, El Salvador. Ver de la página 11 a la 41.

3. Ver Nancy Guillespie, "Los Programas de Ajuste Estructural y la Pobreza". Documento presentado en el curso sobre Administración de la Economía Nacional organizada por la División de Gestión Económica Nacional del IDE que se llevó a cabo en el INCAE, Alajuela, Costa Rica, Sept. de 1989, pp. 1 2.

4. Ver Allonso Goitia "Los Eleclos de las Medidas del Programa del Gobierno", Revista Realidad Económico-Social. Año 11, №. 4, Julio-agosio/89, Publicación de los Departamenlos de Economla, Sociologia y Ciencias Pollticas de la Universidad Centroamericana "José Simeón Cañas", San Salvador, El Salvador, pp. $369-70$.

5. Ver Salvador Arias Peñate, "El Contexto Regional y Mundial de la Estrategia Alternativa de Desarrollo del Isimo Centroamericano". Este artículo aparece como capítulo I del Libro "Democracia sin Pobreza", colección universitaria, Editorial DEL, 1a. Edición, San José Costa Rica. 1992, pp. 72.

6. Ver los resultados de las encuentas de hogares y propósitos múltiples de los perlodos 1988/89, 1991/92, documento publicado en enero de 1993 por el Ministerio de Planificación y Coordinación del Desarrollo Económico y Social.

7. Ibidem.

8. Ver Salvador Arias, op. cit, pp. 65.

9. Ver Otton Solis, PAE: "Los Resultados", arllculo aparecido en el periódico La Nación, 17 de noviembre de 1990, San José, Costa Rica.

10. Ver Francisco Javier Ibisate "El Neoliberalismo no es un dogma de fe", Revista Realidad Económica-Social, año V, No. 29, Septiembre-Octubre/92, pp. 490. 
11. El tipo de cambio utilizado para convertir a dólares las citras del déficit lue de $\$ 5.00 \times$ US $\$ 1.00$ para el perlodo $84-88$, para el siguiente se aplicó una tasa del $\$ 8.50 \times$ US $\$ 1.00$.

12. Roberto Rubio y William Pleitez "Ajuste estructural, término de intercambio internos y la pequeña producción de granos básicos: el caso de El Salvador, Programa Regional de Reforzamiento a la Investigación Agronómica sobre los Granos en Centroamérica (PRIAG), San José, costa Rica. 20/marzo/92.

13. Ver Otton Solls, op. cit.

14. Las cifras oficiales del Banco Central de Reserva reportan la siguiente serie estadistica:
A) 1989
US\$ 203.7
B) 1990 US\$ 322.1
C) 1991 US\$ 543.5
D) 1992 US\$708.6

15. Ver Roberto Rubio, op. cit., pp.

16. Ver Salvador Arias, op. cit., pp. 73.

17. Esta hipótesis fue lanzada por Eduardo Valladares en su artículo "La crisis y las Pollticas de Estabilización y Ajuste en Honduras", Cuadernos de Ciencias Sociales? Facultad Latinoamericana de Ciencias Sociales (FLACSO), lebrero de 1987, San José, Costa Rica, pg. 110. 